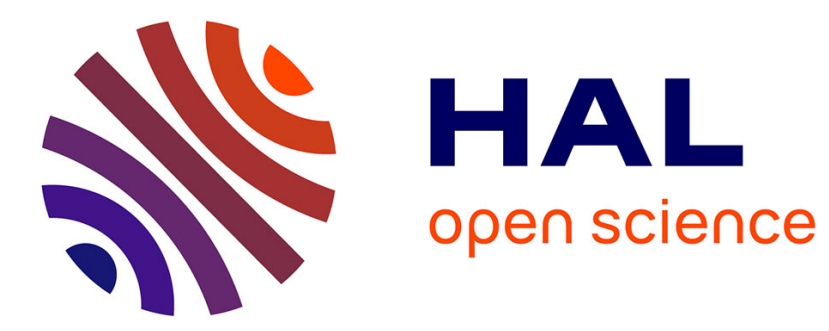

\title{
How do PDMS-coated stir bars used as passive samplers integrate concentration peaks of pesticides in freshwater?
}

\author{
A. Assoumani, C. Margoum, A. Lombard, C. Guillemain, Marina Coquery
}

\section{- To cite this version:}

A. Assoumani, C. Margoum, A. Lombard, C. Guillemain, Marina Coquery. How do PDMS-coated stir bars used as passive samplers integrate concentration peaks of pesticides in freshwater?. Environmental Science and Pollution Research, 2017, 24 (8), pp.6844-6852. 10.1007/s11356-016-6715-0 . hal-01707870

\author{
HAL Id: hal-01707870 \\ https://hal.science/hal-01707870
}

Submitted on 13 Feb 2018

HAL is a multi-disciplinary open access archive for the deposit and dissemination of scientific research documents, whether they are published or not. The documents may come from teaching and research institutions in France or abroad, or from public or private research centers.
L'archive ouverte pluridisciplinaire HAL, est destinée au dépôt et à la diffusion de documents scientifiques de niveau recherche, publiés ou non, émanant des établissements d'enseignement et de recherche français ou étrangers, des laboratoires publics ou privés. 
1 How do PDMS-coated stir bars used as passive samplers integrate

2 concentration peaks of pesticides in freshwater?

3 A. Assoumani, C. Margoum*, A. Lombard, C. Guillemain, M. Coquery

Irstea, UR MALY, centre de Lyon-Villeurbanne, 5 rue de la Doua-CS 70077, F-69626 Villeurbanne cedex, France

*Corresponding author: Tel: + 334722087 11; Email address: christelle.margoum@irstea.fr

8 Abstract

9 Passive samplers are theoretically capable of integrating variations of concentrations of

10 micropollutants in freshwater and providing accurate average values. However, this property

11 is rarely verified and quantified experimentally. In this study, we investigated, in controlled

12 conditions, how the polydimethylsiloxane-coated stir bars (passive Twisters) can integrate

fluctuating concentrations of 20 moderately hydrophilic to hydrophobic pesticides $(2.18<$

$\left.\log \mathrm{K}_{\mathrm{ow}}<5.51\right)$. In the first two experiments, we studied the pesticide accumulation in the passive Twisters during high concentration peaks of various durations in tap water. We then followed their elimination from the passive Twisters placed in non-contaminated water (Experiment $\mathrm{n}^{\circ} 1$ ), or in water spiked at low concentrations (Experiment $\mathrm{n}^{\circ} 2$ ) for one week. In the third experiment, we assessed the accuracy of the time-weighted average concentrations (TWAC) obtained from the passive Twisters exposed for four days to several concentration variations scenarios. We observed little to no elimination of hydrophobic pesticides from the passive Twisters placed in non-contaminated water, and additional accumulation when placed in water spiked at low concentrations. Moreover, passive Twisters allowed determining accurate TWAC (accuracy, determined by TWAC-average measured concentrations ratios, ranged from 82 to $127 \%$ ) for the pesticides with $\log \mathrm{K}_{\mathrm{ow}}$ higher than 4.2 . In contrast, fast and large elimination was observed for the pesticides with $\log \mathrm{K}_{\mathrm{ow}}$ lower than 4.2 and poorer TWAC accuracy (ranging from 32 to $123 \%$ ) was obtained. 
Keywords: Passive sampling, passive SBSE, variations of concentrations, time-weighted average concentrations (TWAC)

\section{Introduction}

Passive sampling allows the determination of representative time-weighted average concentrations (TWAC) of micropollutants such as pesticides in freshwater, for lower logistical and analytical costs than spot sampling at high sampling frequency (Poulier et al 2014). In case of periodic concentration peaks, such as during flood events in small agricultural watersheds, greater attention to the determination of accurate TWAC is needed for ecological risk assessment and decision making. Indeed, floods are a major pathway for the transport of pesticides in rivers located in vineyard watershed (Kreuger 1998; Rabiet et al. 2010). Recent studies demonstrated that the lambda-cyhalothrin peak exposure scenario (10fold higher concentrations for 10 -fold shorter exposure duration) could result in a higher ecotoxicity to aquatic invertebrates such as Gammarus fossarum than a longer exposure period at lower concentrations (Bundschuh et al. 2013).

Based on the commercial laboratory extraction technique Stir Bar Sorptive Extraction (SBSE), the passive SBSE was recently developed for the passive sampling of pesticides in river waters (Assoumani et al. 2013; Assoumani et al. 2014; Assoumani et al. 2015), especially for the integration of transient concentration peaks resulting from flood events. Gerstel Twisters ${ }^{\circledR}$ (herein called "passive Twisters") were exposed without membrane directly in small rivers to accumulate pesticides and integrate transient variations of pesticide concentrations. 
51 The theory of passive sampling is well established and documented (Vrana et al. 2005; Huckins et al. 2006; Greenwood et al. 2007); and the passive SBSE follows the same theory as described by these authors. Assuming isotropic exchange, the accumulation of a micropollutant in a passive Twister over time with constant ambient water concentration obeys a first-order kinetics, described by Eq. 1 (Assoumani et al. 2014):

$$
\mathrm{M}_{\mathrm{s}}(\mathrm{t})=\mathrm{C}_{\mathrm{w}} \mathrm{K}_{\mathrm{sw}} \mathrm{V}_{\mathrm{s}}\left(1-\exp \left(-\frac{\mathrm{R}_{\mathrm{s}} \mathrm{t}}{\mathrm{K}_{\mathrm{sw}} \mathrm{V}_{\mathrm{s}}}\right)\right)
$$

where $\mathrm{M}_{\mathrm{s}}(\mathrm{ng})$ is the mass of micropollutant accumulated in the receiving phase; $\mathrm{C}_{\mathrm{w}}\left(\mathrm{ng} \mathrm{L}^{-1}\right)$ is the concentration of micropollutant in the water phase; $\mathrm{K}_{\mathrm{sw}}$ (adimensional) described by the ratio of the concentration at equilibrium of micropollutant in the receiving phase $\mathrm{C}_{\mathrm{s}}\left(\mathrm{ng} \mathrm{L}^{-1}\right)$ and the concentration at equilibrium of micropollutant in the water phase $C_{w}\left(n g L^{-1}\right)$, is the receiving phase/water partition coefficient; $V_{s}(L)$ is the volume of the receiving phase; $R_{s}$ is the sampling rate $\left(\mathrm{L} \mathrm{d}^{-1}\right)$; and $\mathrm{t}(\mathrm{d})$ is the duration of exposure.

The accumulation kinetics is composed of a linear phase, and then, a curvilinear phase, before reaching the equilibrium. In the initial phase, the linear accumulation is integrative, and defined as follows (Eq. 2):

$$
\mathrm{M}_{\mathrm{s}}(\mathrm{t})=\mathrm{C}_{\mathrm{w}} \mathrm{R}_{\mathrm{s}} \mathrm{t}
$$

During this period, the fluctuations of concentrations are theoretically integrated by the sampler with negligible elimination of micropollutant after the peak events. The accumulation half-life of the micropollutants $\left(\mathrm{t}_{1 / 2}\right)$ is commonly defined as the limit of this linear period, and samplers exposed in the field during this period are therefore expected to provide TWAC (Vrana et al. 2005; Huckins et al. 2006; Greenwood et al. 2007).

In case of linear integrative accumulation, the TWAC $\left(\mathrm{C}_{\mathrm{w}}\right)$ is calculated with the following equation (Eq. 3), derived from Eq. 2: 


$$
\mathrm{C}_{\mathrm{w}}=\frac{\mathrm{M}_{\mathrm{s}}}{\mathrm{R}_{\mathrm{s}} \mathrm{t}}
$$

72 In case of curvilinear accumulation, for instance for exposure periods larger than $\mathrm{t}_{1 / 2}$, TWAC can still be determined with the following equation (Eq. 4):

$$
\mathrm{C}_{\mathrm{w}}=\frac{\mathrm{M}_{\mathrm{s}}}{\mathrm{K}_{\mathrm{sw}} \mathrm{V}_{\mathrm{s}}\left(1-\exp \left(-\frac{\mathrm{R}_{\mathrm{s}} \mathrm{t}}{\mathrm{K}_{\mathrm{sw}} \mathrm{V}_{\mathrm{s}}}\right)\right)}
$$

74 However, during the curvilinear accumulation period, the uptake of micropollutants is not integrative (Vrana et al. 2005; Huckins et al. 2006; Greenwood et al. 2007), and these TWAC might be less accurate, in case the passive sampler is exposed to fluctuating concentrations.

Lately, the behavior of passive samplers regarding fluctuating concentrations has been investigated through modeling and laboratory studies. Gourlay-Francé et al. (2008) modeled the impact of the duration of the linear accumulation period (i.e., the $t_{1 / 2}$ value) of polycyclic aromatic hydrocarbons (PAH) in semipermeable membrane device (SPMD) on the accuracy of the TWAC. Shaw and Mueller (2009) investigated the integration of the pesticides concentration fluctuations by Chemcatcher and the accuracy of TWAC through modeling and laboratory experiments. Hawker (2010) modeled the responses of passive samplers to several patterns of concentration variations of organic micropollutants. On the one hand, these studies showed the capabilities of different passive samplers for integrating various patterns of concentration fluctuations. On the other hand, deviation between the TWAC and the theoretical concentration or the average spot sample concentration reached up to $100 \%$, depending on the passive sampler, the half-life of monitored micropollutants, and the magnitude, time and duration of concentration variations. This shows that (i) further knowledge about how passive samplers integrate concentration peaks is needed, (ii) the deviation of TWAC from the actual average concentrations is sampler- and micropollutantdependent, and (iii) concentration peak experiments in controlled conditions need to be 
performed for new tools such as passive SBSE to fully assess the deviation of the derived TWAC in a context of fluctuating concentrations.

To this end, we designed three laboratory experiments and exposed the passive Twisters to several scenarios of concentration variations. In Experiment $n^{\circ} 1$ and $n^{\circ} 2$, we exposed the passive Twisters to fast and high integration peaks, and then to low concentration levels for seven days. We observed how the passive Twisters integrated the concentration peaks of pesticides, and then, how the pesticides eliminated from the passive Twisters exposed in low concentration level water. And in Experiment n ${ }^{\circ}$ 3, we exposed the passive Twisters to several scenarios of low magnitude variations of concentrations through a four-day flow-through kinetic study and we assessed the accuracy of the derived TWAC.

\section{Experimental}

Chemicals and materials. The 20 pesticides selected for this study belong to different use classes (herbicides, insecticides, and fungicides) and chemical classes (triazines, substituted ureas, triazoles, and organophosphate compounds); they have various physical chemical properties, such as their octanol-water partition coefficient $\left(\log \mathrm{K}_{\mathrm{ow}}\right)$ (Table 1$)$. We selected acetochlor, atrazine, azoxystrobin, chlorfenvinphos, chlorpyrifos, chlorpyrifos-methyl, chlortoluron, 3,4-dichloroaniline (metabolite of diuron), diflufenican, dimethomorph, flufenoxuron, fenitrothion, isoproturon, linuron, metolachlor, norflurazon, procymidon, simazine, spiroxamine, and tebuconazole (all with purity $\geq 92.5 \%$ ), purchased from Dr. Ehrenstorfer GmbH (Augsburg, Germany).

For chemical analyses, diuron-d6 (used as internal standard) was provided by Dr. Ehrenstorfer (purity $\geq 98.5 \%$ ). Ultrapure water was produced by a MilliQ water purification system 
equipped with an LC-Pak cartridge and purchased from Millipore (Billerica, MA, USA). For passive SBSE, we used Twisters ${ }^{\circledR}$ (20 mm x 1-mm thick polydimethylsiloxane (PDMS) film) purchased from Gerstel (Mülheim a/d Ruhr, Germany). For all experiments, the passive Twisters were placed in water in deployment bags, as described elsewhere (Assoumani et al. 2014).

Flow-through experiments. For the flow-through experiments, three levels of pesticides concentrations were selected. In Experiment $n^{\circ} 1$ and $n^{\circ} 2$, a high level of concentrations called 10C (from 2 to $800 \mu \mathrm{g} \mathrm{L}^{-1}$ ) was selected for the concentration peaks simulations (in Supplementary Data section, see the nominal and measured pesticide concentrations during the six-hour concentration peak exposure in Experiment $n^{\circ} 1$ and Experiment n ${ }^{\circ} 2$ in Table S1 and Table S2). In Experiment n ${ }^{\circ}$, two lower levels of concentrations called 1C (from 0.20 to $80 \mu \mathrm{g} \mathrm{L}^{-1}$ ) and $2 \mathrm{C}$ (from 0.40 to $160 \mu \mathrm{g} \mathrm{L}^{-1}$ ) were selected for the evaluation of TWAC accuracy (in Supplementary Data section, see the nominal and measured pesticide concentrations in the contaminated waters at $1 \mathrm{C}$ and $2 \mathrm{C}$ concentration levels in Experiment $\mathrm{n}^{\circ} 3$ in Table S5). The 1C concentration level was chosen as low as possible to approach environment conditions while allowing direct injection analysis of all the pesticides.

To simulate variations of concentrations, different durations of passive Twister exposure as well as different concentration levels were applied. For Experiments $n^{\circ} 1$ and $n^{\circ} 2$, we studied the exposure of the passive Twisters to high concentration (10C) for a short period (two, four and six hours), in order to investigate the capabilities of the passive Twisters to integrate fast and high concentration peaks, as encountered during flood events in small agricultural watersheds. Then, we measured the elimination of the pesticides from the passive Twisters in non-contaminated $(0 \mathrm{C})$ or contaminated water $(1 \mathrm{C})$ for seven days, to determine how long the passive Twisters would keep the pesticide accumulated after the fast concentration peak. In 
Experiment $n^{\circ} 3$, we studied different scenarios of exposure of the passive Twisters to lower concentrations (1C and 2C) for a longer period (four days). And then, we assessed the accuracy of the derived TWAC for each scenario and each pesticide.

All experiments were realized in glass aquariums filled with $17 \mathrm{~L}$ of tap water either nonspiked or spiked at different concentration levels, depending on the experiment. The experiments were realized either in open circuit, i.e., with a continuous renewal of water (spiked or not) in the aquariums, or in closed circuit, i.e., without renewal of the water, as described for each experiment. For the renewal of non-spiked water, tap water flow was 71 $\mathrm{mL} \cdot \mathrm{min}^{-1}$ for each aquarium, ensuring six renewals of the water a day (in Supplementary Data section, see the schematized systems of Experiment $n^{\circ} 1$ in Figure S1). For the renewal of spiked water, the pesticide stock solution and tap water were continuously brought into a mixing vessel (in Supplementary Data section, see the schematized systems of Experiment $n^{\circ} 2$ in Figure $\mathrm{S} 2$ ). Then, the flow of freshly prepared spiked tap water in each aquarium was $71 \mathrm{~mL} \cdot \mathrm{min}^{-1}$, ensuring six renewals of the water a day. The aquariums were equipped with one or two diffusion ramps -each one connected to an immersed pump (New Jet 1200, Aquarium Systems NEWA, Italy) creating the water flows (in Supplementary Data section, see Figure S3). Each ramp was composed of four holes, through which the water went out at $20 \mathrm{~cm} \cdot \mathrm{s}^{-1}$. The passive Twisters were placed in deployment bags. The deployment bags were attached to stainless steel sticks, which were plunged in the water so that the passive Twisters were placed in front of each hole of the diffusion ramp, in the water flow during the experiment (Figure S3). All three experiments were realized at $20 \pm 1^{\circ} \mathrm{C}$; all aquariums were placed in a bath of temperature-controlled water. The temperature of the water of each aquarium was monitored continuously with a data logger (Tiny tag Aquatic 2).

In Experiment $n^{\circ} 1$, three batches of 10 passive Twisters were placed simultaneously in an aquarium filled with tap water spiked with the target pesticides at high concentration level 
167 (10C) (Figure S1). To simulate concentration peaks of different durations and to assess their integration of the concentration peaks, one batch of 10 passive Twisters was exposed for two hours to high pesticide concentration (10C), another one for 4 hours, and the last batch for 6 hours. Water samples were collected at the beginning of the experiment, and then every 15 min for 6 hours to monitor the water concentration of the pesticides (in Supplementary Data section, see the nominal and measured pesticide concentrations during the six-hour concentration peak exposure in Experiment $n^{\circ} 1$ and Experiment $n^{\circ} 2$ in Table $\mathrm{S} 1$ and Table S2). The concentration peak exposures were realized in a closed circuit. We spiked the tap water with a stock solution of the 20 pesticides at the beginning of the six-hour experiment. According to a previous study (unpublished data), besides the initial spiking of all pesticides, additional spiking of chlorpyrifos, chlorpyrifos-methyl, and diflufenican was realized every hour to keep their concentration constant.

After the concentration peak exposures, for the three batches of passive Twisters, seven passive Twisters out of ten were placed (in the same deployment bags) in three aquariums filled with non-contaminated tap water to study the elimination kinetics of the target pesticides for seven days. One passive Twister was collected every day, for seven days, and placed at $-18{ }^{\circ} \mathrm{C}$ until chemical analysis, to determine the mass of remaining sorbed pesticides. The three remaining passive Twisters of each batch were placed directly at $-18{ }^{\circ} \mathrm{C}$ before chemical analysis; they constituted the initial point of the elimination kinetics. For the study of the elimination kinetics in Experiment $n^{\circ} 1$, the three aquariums were in open circuit. Fresh tap water was provided at a flow rate of $71 \mathrm{~mL} \mathrm{~min}{ }^{-1}$, to replace the water of the aquarium (17 L) six times a day. After one hour of exposure of the passive Twisters in noncontaminated tap water $(0 \mathrm{C})$, a water sample was collected in the three aquariums and analyzed directly by solid phase extraction and ultra-high performance liquid chromatography coupled to tandem mass spectrometry (SPE-UHPLC-MS/MS) (in Chemical analysis of water 
samples and passive Twisters section, see the analysis conditions). The concentrations of the pesticides in the water were checked once, soon after the deployment of the passive Twisters. We supposed this was the moment when the elimination of the pesticides was the largest. This was to check that, with the elimination of the pesticides, the volume of the non-contaminated water and renewal rate of water were sufficient to ensure negligible pesticide concentrations (0C) in comparison with $1 \mathrm{C}$ concentrations.

Experiment $n^{\circ} 2$ was similar to Experiment $n^{\circ} 1$ regarding the concentration peak exposures, but for the elimination kinetics, the passive Twisters were plunged in tap water spiked at low concentration level 1C (in Supplementary Data section, see the schematized systems of Experiment $\mathrm{n}^{\circ} 2$ in Figure S2). To ensure constant water concentrations for seven days, a continuous spiking of all target pesticides was realized. Water samples were collected every day for seven days in the three aquariums, and stored at $-18^{\circ} \mathrm{C}$ until the chemical analysis. In Experiment $n^{\circ} 3$, seven batches of passive Twisters were exposed to seven scenarios of low concentration level exposures from $0 \mathrm{C}$ to $2 \mathrm{C}$ during four days (Table 2) (in Supplementary Data section, see the schematized system of Experiment $n^{\circ} 3$ in Figure S4). For scenarios $n^{\circ} 1,2$ and 7, the passive Twisters were exposed for four days to constant concentrations of pesticides, at $0 \mathrm{C}, 1 \mathrm{C}$ and $2 \mathrm{C}$, respectively. For scenarios $\mathrm{n}^{\circ} 3$ to 6 , the passive Twisters were exposed to daily variations of concentrations. Three aquariums in flow-through mode were used for this experiment, with a continuous spiking of the pesticides for concentration levels $1 \mathrm{C}$ and $2 \mathrm{C}$, to ensure constant concentrations. Water samples were taken every day for seven days in the aquariums. For each scenario, six passive Twisters were used to follow the accumulation kinetics of the pesticides. One passive Twister was collected on the first three days, and a triplicate of passive Twisters was collected on the last day to determine the mass of accumulated pesticides and calculate the TWAC. 
217 Treatment of passive Twisters. Prior to the three experiments, the passive Twisters were

placed at $300{ }^{\circ} \mathrm{C}$ for an hour for thermal conditioning in the Tube Conditioner from Gerstel.

The passive Twisters collected during the experiments were taken out of their deployment bags, gently rinsed with ultrapure water, dried with Kimwipes ${ }^{\circledR}$ precision paper, and then stored at $-18{ }^{\circ} \mathrm{C}$ until chemical analysis.

Chemical analysis of water samples and passive Twisters. Pesticide concentrations in water samples at $1 \mathrm{C}, 2 \mathrm{C}$ and $10 \mathrm{C}$ concentration levels were determined in direct injection by UHPLC-MS/MS. Water samples at 0C concentration level were analyzed by SPE-UHPLCMS/MS. Before extraction and determination of pesticide concentrations, all water samples were filtered with $0.7 \mu \mathrm{m} \mathrm{GF/F}$ glass fiber membranes. The SPE was realized with Oasis HLB cartridges from Waters $(3 \mathrm{~mL}, 60 \mathrm{mg}$ ). Briefly, the cartridges were first conditioned with subsequently $3 \mathrm{~mL}$ of acetonitrile, $3 \mathrm{~mL}$ of methanol, and $3 \mathrm{~mL}$ of ultrapure water. Then, $250 \mathrm{~mL}$ of water sample was charged on the cartridges at $10 \mathrm{~mL} \cdot \mathrm{min}^{-1}$ flow rate. Then $2 \mathrm{~mL}$ of ultrapure water was passed through the cartridge, before the elution with $6 \mathrm{~mL}$ of acetonitrile. The extract was then evaporated to dryness, and the sample was reconstituted in $250 \mu \mathrm{L}$ of a water-acetonitrile mix $(80 / 20, \mathrm{v} / \mathrm{v})$ spiked with diuron-d6 at $10 \mu \mathrm{g} . \mathrm{L}^{-1}$; the concentration factor was 1000 . Pesticides accumulated in the passive Twisters were desorbed and determined by an analytical method that has been published elsewhere (Margoum et al. 2013). Briefly, the passive Twisters were then placed in $200 \mu \mathrm{L}$ of methanol/acetonitrile $(50 / 50, \mathrm{v} / \mathrm{v})$, and the pesticides were desorbed under sonication for $15 \mathrm{~min}$. Finally, $150 \mu \mathrm{L}$ of ultrapure water and $10 \mu \mathrm{L}$ of diuron-d6 at $200 \mu \mathrm{g} \mathrm{L} \mathrm{L}^{-1}$, in acetone, were added to $40 \mu \mathrm{L}$ of the desorbate to constitute the sample for chemical analysis.

The chemical analyses were performed with a LC Nexera apparatus from Shimadzu (Marnela-Vallée, France) coupled with a MS triple quadrupole API 4000 from AB Sciex (Les Ulis, 
France), equipped with an electrospray ionization source (ESI) that was operated in the positive ionization mode. An HSS T3 column $\left(2.1 \mathrm{~mm} \times 100 \mathrm{~mm} ; \mathrm{d}_{\mathrm{p}}=1.8 \mu \mathrm{m}\right)$ purchased from Waters (St Quentin-en-Yvelines, France) was used for the chromatographic separation of the analytes in $15 \mathrm{~min}$. Acetonitrile and ultrapure water both with formic acid $(0.1 \%)$ were used in an analytical gradient from 10 to $90 \%$ acetonitrile in 10 min (Margoum et al. 2013).

\section{Results and discussion}

Accumulation and desorption kinetics (Experiment $\mathbf{n}^{\circ} \mathbf{1}$ and $\left.\mathbf{n}^{\circ} 2\right)$. Figure $1 \mathrm{a}$ and Figure $1 \mathrm{~b}$ show the accumulation kinetics of simazine and chlorpyrifos, respectively, in passive Twisters exposed to a six-hour concentration peak. Simazine and chlorpyrifos present different hydrophobicites and will be taken as examples in this study to graphically illustrate the behaviors we observed from one pesticide to another. Fast accumulation in the passive Twisters was observed for both pesticides. The masses of pesticides measured in the passive Twisters after two, four, and six hours at 10C showed fast accumulation of all pesticides without lag-time, as reported in our previous study (Assoumani et al. 2014). In both experiments, the $10 \mathrm{C}$ concentration level caused saturation of the passive Twister PDMS phase for hydrophilic pesticides with $\log \mathrm{K}_{\mathrm{ow}}<3$ after two or four hours of exposure, depending on the hydrophobicity of the micropollutant. The measured water concentrations at $10 \mathrm{C}$ level for both six hour-accumulation experiments and the accumulation kinetics of all pesticides in both experiments are presented in Supplementary Data section in Table S1 and in Figure S5, respectively. So, for these hydrophilic pesticides, the passive Twisters could not integrate concentration peaks for more than two or four hours, depending on the hydrophobicity of the micropollutant. In contrast, in Experiment $n^{\circ} 1$, linear accumulations were observed for more hydrophobic micropollutants such as spiroxamine, fenitrothion, diflufenican, chlorpyrifos, chlorpyrifos-methyl, and flufenoxuron. Therefore, passive Twisters 
were capable of rapidly integrating high concentration peaks of these pesticides for up to six hours. In Experiment $n^{\circ} 2$, linear accumulations were observed only for chlorpyrifos and flufenoxuron. Slightly faster accumulation rates than Experiment $n^{\circ} 1$, possibly due to higher average water temperature $\left(21^{\circ} \mathrm{C}\right.$ instead of $20^{\circ} \mathrm{C}$ in Experiment $\left.\mathrm{n}^{\circ} 1\right)$, might explain faster saturation for spiroxamine, fenitrothion, diflufenican, and chlorpyrifos-methyl. Indeed, Booij et al. (2003) showed that the sampling rates of PAH and polychlorobiphenyls (PCB) in SPMD and low-density polyethylene (LDPE) stripes increased by a 1.5 factor with a $10{ }^{\circ} \mathrm{C}$ increase in water temperature.

After exposure to concentration peaks, different behaviors were observed for the target pesticides, depending on their hydrophobicity and the experiment. In this paper, we discuss only the results regarding the passive Twisters exposed to $10 \mathrm{C}$ concentration level for six hours, since, for all pesticides except spiroxamine, chlorpyrifos-methyl, fenitrothion, diflufenican, chlorfenvinphos (all in Experiment $\mathrm{n}^{\circ}$ ), similar behaviors were obtained after four hours and two hours of exposure (in the Supplementary Data section, see the monitoring of all pesticides sorbed in the passive Twisters exposed for seven days to non-contaminated water and contaminated water in Figure S6 and Figure S7). Figure 2a and 2b show the results of both seven-day kinetic experiments for simazine and chlorpyrifos, after the six-hour exposure at $10 \mathrm{C}$ concentration level. In Experiment $\mathrm{n}^{\circ} 1$, up to $78 \%$ of the mass of simazine was eliminated from the passive Twisters in three days and $92 \%$ in seven days, due to the low affinity of this hydrophilic pesticide with the PDMS phase of the passive Twisters. In Experiment $n^{\circ} 2,30 \%$ of simazine initially sorbed in the passive Twisters was eliminated in four days. No further elimination was observed because the concentration of simazine remaining in the passive Twister probably was in equilibrium with the concentration of simazine in the water (in the Supplementary Data section, see the water concentrations during the elimination kinetics of Experiment $n^{\circ} 1$ and Experiment $n^{\circ} 2$ in Table S3 and Table S4, 
respectively). In contrast, chlorpyrifos was not eliminated from the passive Twisters in Experiment $n^{\circ} 1$, and additional accumulation was observed in Experiment $n^{\circ} 2$ (Figure 2b), in accordance with passive sampling theory, as described in the Introduction section (Vrana et al. 2005; Huckins et al. 2006; Greenwood et al. 2007).

Table 1 shows the trend of the elimination kinetics of all target pesticides in Experiments $n^{\circ} 1$ and $n^{\circ} 2$ after six hours of exposure at $10 \mathrm{C}$ concentration level. Results of Experiment $n^{\circ} 1$ showed that most pesticides previously accumulated in the passive Twisters were eliminated rapidly within one to four days and were completely eliminated after being exposed for seven days to non-contaminated water (in the Supplementary Data section, see the monitoring of all tested pesticides sorbed in the passive Twisters exposed for seven days to non-contaminated water in Figure S6). Only the masses of chlorpyrifos and flufenoxuron sorbed in the PDMS phase remained relatively constant, with elimination rates of 0 and $24 \%$, respectively.

In the case of Experiment $\mathrm{n}^{\circ} 2$, acetochlor, 3,4-dichloroaniline, linuron, metolachlor, procymidon were eliminated rapidly but only partially from the passive Twisters exposed for seven days to contaminated water (1C); their concentration in the receiving phase reached equilibrium with the water phase concentration within one to two days (in the Supplementary Data section, see the monitoring of all tested pesticides sorbed in the passive Twisters exposed for seven days to contaminated water in Figure S7). Slower elimination was observed for atrazine, azoxystrobine, simazine, chlorfenvinphos, chlorpyrifos-methyl, chlortoluron, diflufenican, fenitrothion, norflurazon, and tebuconazole. The mass of dimethomorph, isoproturon, and spiroxamine sorbed in the passive Twisters remained relatively constant over the whole experiment; with elimination rates ranging from 0 to $10 \%$. This confirms the saturation observed during the concentration peak simulations. Finally, the masses of chlorpyrifos and flufenoxuron sorbed in the PDMS phase increased for seven days. 
Hence, passive Twisters showed the ability to integrate fast and high concentration peaks of spiroxamine, fenitrothion, diflufenican, chlorpyrifos, chlorpyrifos-methyl, and flufenoxuron, and to possibly provide accurate TWAC after 7 days exposed in non-contaminated or contaminated water for chlorpyrifos and flufenoxuron.

Evaluation of TWAC accuracy (Experiment $\mathbf{n}^{\circ} \mathbf{3}$ ). Water concentrations of all pesticides for $1 \mathrm{C}$ and $2 \mathrm{C}$ concentration levels dropped over the four-day experiments despite the continuous spiking (in the Supplementary Data section, see the water concentrations of the 1C and $2 \mathrm{C}$ levels during the accumulation kinetics in Table S5). Decreases rates ranged from 16 $\%$ for chlorpyrifos-methyl up to $74 \%$ for flufenoxuron for the 1C concentration level, and from $10 \%$ for diflufenican to $65 \%$ for flufenoxuron for the $2 \mathrm{C}$ concentration level. The scenario $n^{\circ} 2$ and $n^{\circ} 7$ were used to study the accumulation kinetics of all pesticides passive Twisters exposed to constant $1 \mathrm{C}$ and $2 \mathrm{C}$ concentration levels, respectively, for four days. The accumulation kinetics of simazine and chlorpyrifos in passive Twisters exposed to $1 \mathrm{C}$ and $2 \mathrm{C}$ concentration levels are showed in Figure $3 \mathrm{a}$ and Figure 3b, respectively. For all pesticides except for spiroxamine, chlorpyrifos, chlorpyrifos-methyl, flufenoxuron, and diflufenican, equilibrium (or saturation) was reached on the first or second day at $1 \mathrm{C}$ concentration level, and even faster at $2 \mathrm{C}$ concentration level (in Supplementary Data section, see the accumulation kinetics of all pesticides in the passive Twisters exposed to constant $1 \mathrm{C}$ and $2 \mathrm{C}$ concentration levels for four days in Figure S8). Water concentrations were chosen as low as possible while allowing direct injection analysis. The level of water concentrations, however probably too high, the small volume of PDMS phase of the passive Twisters, and the decrease in the water concentrations can explain that equilibrium was reached surprisingly fast. Indeed, Booij and Tucca (2015) recently showed that the decrease of the ambient concentration can make the accumulation of micropollutant in a passive sampler reach the equilibrium faster. In 
contrast, linear and curvilinear accumulations were observed for more hydrophobic spiroxamine, diflufenican, chlorpyrifos, chlorpyrifos-methyl and flufenoxuron.

For scenarios $n^{\circ} 2$ to $n^{\circ} 6$, the TWAC $\left(C_{w}\right)$ were calculated with the mass of all pesticides accumulated in the passive Twisters at the end of the experiment (day 4) and with Eq. 4. The sampling rate $\left(\mathrm{R}_{\mathrm{s}}\right)$ and the partition coefficient $\left(\mathrm{K}_{\mathrm{sw}}\right)$ of all studied pesticides were determined with the accumulation kinetics obtained from scenario $n^{\circ} 2$, Eq. 1 and the Solver tool in Microsoft Excel software. To evaluate the accuracy of the TWAC derived from the passive SBSE in scenarios $n^{\circ} 2$ to $n^{\circ} 6$, we calculated the ratios between the TWAC $\left(C_{w}\right)$ and the average value of the measured water concentrations $(\overline{\mathrm{C}})$ during the four-day exposure, obtained by the analysis of the spot samples (in Supplementary Data section, see the measured pesticide concentrations in the contaminated waters at $1 \mathrm{C}$ and $2 \mathrm{C}$ concentration levels in Table S5).

Figure 4a shows the distribution of the accuracy of all pesticides for the five scenarios. As expected for scenario $\mathrm{n}^{\circ} 2$, we observed accuracy close to $100 \%$ for all pesticides. Scenarios $n^{\circ} 3$ and $n^{\circ} 6$ ended with one or two days of exposure at $2 \mathrm{C}$ concentration level; the passive Twisters accumulated the target pesticides while little to no elimination occurred. Therefore, average accuracy of $124 \%$ for scenario $\mathrm{n}^{\circ} 3$ and $106 \%$ for scenario $\mathrm{n}^{\circ} 6$ were observed, although with large variability. Average accuracy of $53 \%$ and $46 \%$ were observed for scenario $n^{\circ} 4$ and scenario $n^{\circ} 5$, respectively, which ended with one or two days of exposure to non-contaminated tap water. In these cases, the most hydrophilic pesticides were rapidly eliminated from the passive Twisters, as observed in Experiment $n^{\circ} 1$ (Figure S6). The observed average accuracy imply that the scenario has an impact on the value of average concentration. When the variation of concentration occurs just before the end of the sampling period, the average concentration is closer to the actual value. These results are in good agreement with the work of Shaw and Mueller (2009) with the Chemcatcher. The authors 
predicted through simulation that a herbicide concentration peak event is better represented by the sampler (under curvilinear accumulation kinetics) when it occurs towards the end of the sampling period. Figure $4 \mathrm{~b}$ displays the distribution of the accuracy for the five scenarios for spiroxamine, diflufenican, chlorpyrifos, chlorpyrifos-methyl, and flufenoxuron. Better accuracy was observed for these five hydrophobic pesticides, with average accuracy ranging from 82 to $127 \%$ depending on the scenario. In that case, the moment when the variation of concentration occurred during the sampling period had less impact on the average concentrations because the sampling of these pesticides by the passive Twisters was more integrative. Indeed, they showed little to no elimination in four days in Experiment $n^{\circ} 1$ (except for chlorpyrifos-methyl) (Figure S6), and their accumulation kinetics were more linear (Experiment $n^{\circ} 3$ ) (Figure S8).

Can passive SBSE determine accurate TWAC? Linear accumulation and integrative sampling are obviously preferable for the determination of accurate TWAC by passive SBSE (Greenwood et al. 2007; Assoumani et al. 2014). However in practice, curvilinear accumulation might occur because, for instance, passive Twisters might be exposed for periods longer than the linear accumulation period. The integration of a concentration peak or the exposure of the sampler to decreasing water concentrations could also lower the $t_{1 / 2}$ value, and shorten the linear accumulation period (Hawker 2010; Booij and Tucca 2015). Therefore, the ability of the passive Twisters in curvilinear sampling for providing accurate enough concentrations needs to be assessed for future field applications of the passive SBSE.

In case passive Twisters are exposed to constant concentrations, Eq. 4 allows calculating TWAC with good accuracy. Indeed, we obtained an average accuracy of $95 \%$ for the TWAC of 20 studied pesticides in the scenario $n^{\circ} 2$ of the Experiment $n^{\circ} 3$. The error in the TWAC accuracy comes from the difference between the model and the real mass of micropollutant 
accumulated, which is determined with an analytical uncertainty. Scenario $\mathrm{n}^{\circ} 2$ showed that, for the 20 pesticides with different physical chemical properties and kinetic patterns, this error was lower than $20 \%$. Considering an average analytical uncertainty of $20 \%$ for the determination of pesticides in water samples (Margoum et al. 2013), this error on the TWAC accuracy is satisfactory.

In case of fluctuating concentrations at the daily scale, the present investigation allowed us to highlight two groups of pesticides, in relation with their hydrophobicity. First, on the basis of the results of Experiment $n^{\circ} 3$, the pesticides with $\log \mathrm{K}_{\mathrm{ow}}<4.2$ might provide TWAC with poor average accuracy (33\% for scenario $n^{\circ} 5$ and $39 \%$ for scenario $n^{\circ} 4$ ) in case the concentration variation occurred at the beginning of the sampling campaign. Nevertheless, although these pesticides showed short accumulation periods in laboratory conditions, in field conditions, passive Twisters may accumulate linearly these hydrophilic pesticides for a period larger than 2 days. A field calibration of the passive Twisters is needed to confirm this hypothesis. Second, linear and curvilinear accumulations, and average accuracy ranging from 82 to $127 \%$ depending on the scenario (Experiment $n^{\circ} 3$ ) for diflufenican, spiroxamine, chlorpyrifos, chlorpyrifos-methyl, flufenoxuron showed that the passive SBSE could provide concentrations with an error comparable to the analytical uncertainty in case of fluctuating concentrations.

\section{Conclusion}

Pesticide concentrations in rivers of small vineyard watersheds generally vary according to fluctuation of hydrological conditions, and especially during storm events. This works aimed at determining the capabilities of the passive Twisters for integrating variations of concentrations of 20 moderately hydrophilic to hydrophobic pesticides, and their accuracy for 
the determination of TWAC. In the first two experiments, we observed integration of fast and high concentration peaks for spiroxamine, fenitrothion, diflufenican, chlorpyrifos, chlorpyrifos-methyl, and flufenoxuron. We also observed little to no elimination from the passive Twisters when exposed to non-contaminated water and additional accumulation when exposed to water spiked at low concentrations for chlorpyrifos and flufenoxuron. The results of the third experiment showed that passive Twisters could provide TWAC of hydrophobic pesticides such as diflufenican, spiroxamine, chlorpyrifos, chlorpyrifos-methyl, flufenoxuron with average accuracy ranging from 82 to $127 \%$, depending on the scenario. In contrast, TWAC with average accuracy ranging from 33 to $123 \%$, depending on the scenario, were obtained for the pesticides with $\log \mathrm{K}_{\mathrm{ow}}<4.2$, due to fast and great elimination from the passive Twisters.

\section{Acknowledgments}

The authors thank the Ecophyto program and the French National Agency for Water and Aquatic Environments (ONEMA) for financial support.

\section{References}

Assoumani A, Coquery M, Liger L, Mazzella N, Margoum C (2015) Field Application of Passive SBSE for the Monitoring of Pesticides in Surface Waters. Environ Sci Pollut Res 22: 3997-4008. doi:10.1007/s11356-014-3590-4

Assoumani A, Lissalde S, Margoum C, Mazzella C, Coquery M (2013) In Situ Application of Stir Bar Sorptive Extraction as a Passive Sampling Technique for the Monitoring of Agricultural Pesticides in Surface Waters. Sci Tot Environ 463-464: 829-835. doi:10.1016/j.scitotenv.2013.06.025.

Assoumani A, Margoum C, Chataing S, Guillemain C, Coquery M (2014) Use of Passive Stir Bar Sorptive Extraction as a Simple Integrative Sampling Technique of Pesticides in Freshwaters: Determination of Sampling Rates and Lag-Phases. J Chromatogr A 1333: 1-8. doi:10.1016/j.chroma.2014.01.063

Booij K, Hofmans HE, Fischer CV, Van Weerlee EM (2003) Temperature-Dependent Uptake Rates of Nonpolar Organic Compounds by Semipermeable Membrane Devices and 
Low-Density Polyethylene Membranes. Environ Sci Technol 37: 361-366. doi:10.1021/es025739i

Booij K, Tucca F (2015) Passive Samplers of Hydrophobic Organic Chemicals Reach Equilibrium Faster in the Laboratory than in the Field. Marine Pollut Bull 98: 365367. doi:10.1016/j.marpolbul.2015.07.007

Bundschuh M, Zubrod JP, Klemm P, Elsaesser D, Stang C, Schulz R (2013) Effects of Peak Exposure Scenarios on Gammarus Fossarum Using Field Relevant Pesticide Mixtures. Ecotoxicol Environ Safety 95:137-143. doi:10.1016/j.ecoenv.2013.05.025

Gourlay-Francé C, Lorgeoux C, Tusseau-Vuillemin MH (2008) Polycyclic Aromatic Hydrocarbon Sampling in Wastewaters Using Semipermeable Membrane Devices: Accuracy of Time-Weighted Average Concentration Estimations of Truly Dissolved Compounds. Chemosphere 73: 1194-1200. doi:10.1016/j.chemosphere.2008.07.049

Greenwood R, Mills G, Vrana B (2007) Passive Sampling Techniques in Environmental Monitoring (Comprehensive Analytical Chemistry, Vol. 48), Elsevier Science.

Hawker, DW (2010) Modeling the Response of Passive Samplers to Varying Ambient Fluid Concentrations of Organic Contaminants. Environ Toxicol Chem 29: 591-596. doi:10.1002/etc.69

Huckins JN, Petty JD, Booij K (2006) Monitors of Organic Chemicals in the Environment: Semipermeable Membrane Devices. Springer, New York

Kreuger, J (1998) Pesticides in Stream Water within an Agricultural Catchment in Southern Sweden, 1990-1996. Sci Tot Environ 216: 227-251. doi:10.1016/S00489697(98)00155-7

Margoum C, Guillemain C, Yang X, Coquery M (2013) Stir Bar Sorptive Extraction Coupled to Liquid Chromatography-Tandem Mass Spectrometry for the Determination of Pesticides in Water Samples: Method Validation and Measurement Uncertainty. Talanta 116: 1-7. doi:10.1016/j.talanta.2013.04.066

Poulier G, Lissalde S, Charriau A, Buzier R, Delmas F, Gery K, Moreira A, Guibaud G, Mazzella N (2014) Can POCIS be used in Water Framework Directive (2000/60/EC) monitoring networks? A study focusing on pesticides in a French agricultural watershed. Sci Tot Environ 497-498: 282-292. doi:10.1016/j.scitotenv.2014.08.001

Rabiet M, Margoum C, Gouy V, Carluer N, Coquery M (2010) Assessing Pesticide Concentrations and Fluxes in the Stream of a Small Vineyard Catchment - Effect of Sampling Frequency. Environ Pollut 158: 737-748. doi:10.1016/j.envpol.2009.10.014

Shaw M, Mueller JF (2009) Time Integrative Passive Sampling: How Well Do Chemcatchers Integrate Fluctuating Pollutant Concentrations? Environ Sci Technol 43: 1443-1448. doi:10.1021/es8021446

Vrana B, Mills GA, Allan IJ, Dominiak E, Svensson K, Knutsson J, Morrison G, Greenwood R (2005) Passive Sampling Techniques for Monitoring Pollutants in Water. TRACTrends Anal Chem 24: 845-868. doi:10.1016/j.trac.2005.06.006 